\title{
Abkürzungsverzeichnis
}

\author{
Immunologie - Ein Nachschlagewerk
}

\author{
AAB Antigen-Antikörper-Bindung(en) \\ AAK Antigen-Antikörper-Komplex(e) \\ AAR Antigen-Antikörper-Reaktion(en) \\ Ag Antigen(e) \\ Ak Antikörper \\ ALS Antilymphozytenserum \\ bzw. beziehungsweise \\ biol. biologisch \\ dgl. dergleichen \\ d.h. das heißt \\ DD Differentialdiagnose(n) \\ dd differentialdiagnostisch \\ Di Diagnose(n) \\ di diagnostisch \\ IE Internationale Einheit(en) \\ IK Immunkomplex(e) \\ KB Komplementbindung \\ KBR Komplementbindungsreaktion
}

MG Molekulargewicht

Serol. Serologie

serol. serologisch

Th Therapie

th therapeutisch

u. a. unter anderem

usw. und so weiter

z. B. zum Beispiel

z. T. zum Teil 

IMM UNOLOG IE ein Nachschlagewerk 


\title{
IMMUNOLOGIE
}

\author{
ein Nachschlagewerk
}

2., bearbeitete Auflage

Herausgegeben von

Doz. Dr. med. habil. GERHARD BUNDSCHUH

und Prof. Dr. med. habil. BURKHARD SCHNEEWEISS 


\title{
IMMUNOLOGIE
}

\section{ein Nachschlagewerk}

\author{
2., bearbeitete Auflage
}

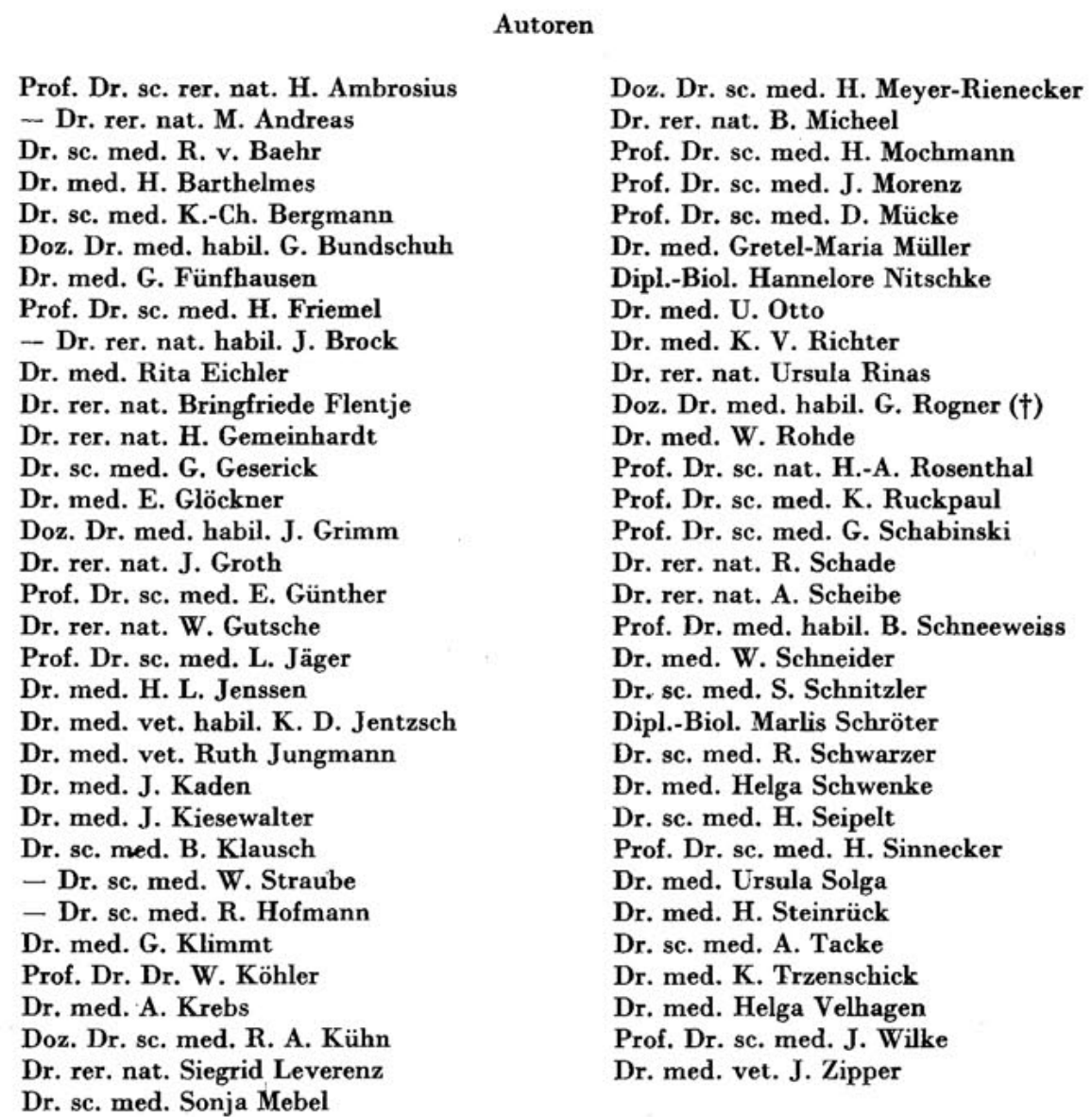

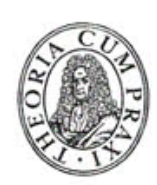

A K A D E M I E - VE RLAG - B E RL I N 
Erschienen im Akademie-Verlag, 108 Berlin, Leipziger Straße 3-4

(c) Akademie-Verlag Berlin 1976

Lizenznummer: $202 \cdot 100 / 522 / 78$

Einband und Schutzumschlag: Rolf Kunze

Gesamtherstellung: VEB Druckhaus ,Maxim Gorki“", 74 Altenburg

Bestellnummer: 7618887 (6135) · LSV 2105

Printed in GDR

DDR 42,- M 
Unserem verehrten Lehrer, dem wir die Begeisterung an der Immunologie verdanken, Herrn Professor Dr: O. Prokop 
